\title{
GDC calls for views on its strategy
}

The General Dental Council (GDC) has launched a consultation on its strategy for 2020-22 'Working with the dental team for public safety and confidence.' The consultation seeks, for the first time, a conversation about the choices to be made in delivering the regulator's broad statutory objectives.

The strategy reflects the significant progress the GDC has made against its ambitions to make dental regulation better and fairer - as described in 'Shifting the balance' - and the many difficult decisions taken to reduce costs and improve effectiveness.

The strategy sets out a vision for the GDC to:

- Protect patients while being fair to registrants, cost-effective and proportionate: by focusing on education and engagement, supporting career-long learning and promoting high standards of care and professional conduct

- Work with the professions and partners to ensure that public concerns can be addressed by the right body, quickly and effectively

- Use evidence, research and evaluation to ensure enforcement is cost-effective and right-touch

- Ensure its approach to regulation keeps pace with change

- Continue to build on the considerable improvements it has made.

This is a key moment for dental regulation and the GDC is calling on professionals, partners and the public to engage and support this work.

Whilst the GDC is clear that this is not a consultation on fee levels, it recognises that those levels are fundamentally affected by the costs of the Strategy and addresses the annual retention free (ARF) accordingly. Because of the significant achievements that have been made in improving financial control and reducing costs, the GDC is expecting the strategy to be consistent with a significant reduction in the ARF for dentists and only a very small increase in the fee level for dental care professionals (DCPs)

The consultation is open now and can be accessed via www.gdc-uk.org. The deadline to respond is Thursday 30 July 2019.

\section{Editor Q\&A: Mark Greenwood}

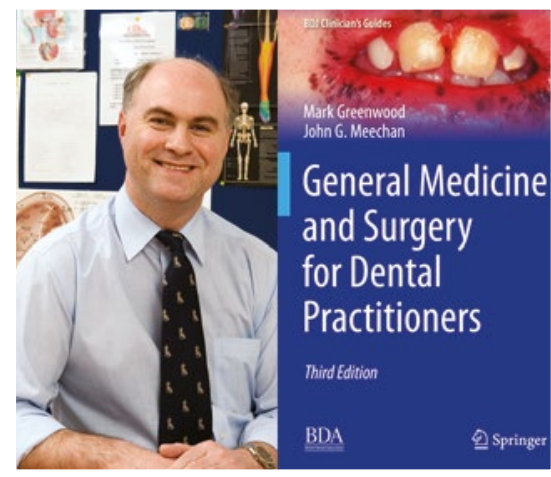

The $B D J$, in association with the British Dental Association (BDA), has published the third edition of General medicine and surgery for dental practitioners, ${ }^{1}$ part of the series of books: the BDJ Clinician's Guides. This series builds on the trusted BDJ Clinical Guides, creating books that update and inform the busy clinician on key topics across all fields of dentistry. Each volume is authored by recognised experts, superbly illustrated and provides concise, highly practical guidance and solutions. For General medicine and surgery for dental practitioners, we spoke to the lead editor Mark Greenwood to find out more about it.

\section{Why should people read this book?}

This book should hopefully be of some use to any part of the dental team. It covers the basics that are needed to underpin safe practice in terms of general medical and surgical knowledge. The growth of internet resources can lead to less of this material being covered on the undergraduate curriculum. I am convinced that patients would expect their dentists to have a good grounding in this area and have a solid understanding of the conditions that they will tell their dentists about.

\section{Who is it aimed at?}

The book (now in its third edition, with co-author Dr J. G. Meechan) is aimed at undergraduate students, dental practitioners and postgraduates preparing for the various exams of the Royal Colleges of Surgeons.

\section{Did you enjoy writing it?}

I enjoyed writing it because it is an area in which I have devoted a lot of my efforts to teaching and find the subject matter interesting and am keen to communicate it.

\section{What made you write it?}

I think that too many books in this area have historically been written by medical doctors who often have a different perspective on what they think that dentists need to know in the medical area. This sometimes means too much of a knowledge requirement (but often assumes that little knowledge is required!).
What are the key issues in this area?

Clearly some issues are more important than others, for example having a good working knowledge of the cardio-respiratory systems and how they may directly impact on dental care. I think it is critical for a rounded clinician to have a broad medical knowledge of all systems to underpin their clinical practice.

\section{Any advice for future authors of BD. Clinician's Guides?}

Try and identify a 'gap in the market' and write something that people will hopefully see as relevant and want to read.

\section{What do you do in your spare time?} Spend time with family. I am a keen pianist and like watching old (mainly British) black and white films.

\section{What other dentistry books would you highly recommend?}

There are too many good ones to single out but any that are well illustrated and relevant.

\section{References}

1. Greenwood M, Meechan J. General medicine and surgery for dental practitioners. $3^{\text {rd }}$ edition. London: Springer Nature, 2019. Available at https://shop.bda. org/general-medicine-and-surgery-for-dental-practitioners (accessed May 2019). 